\title{
Cost analysis of magnetically controlled growing rods compared with traditional growing rods for early-onset scoliosis in the US: an integrated health care delivery system perspective
}

\author{
This article was published in the following Dove Press journal: \\ ClinicoEconomics and Outcomes Research \\ 14 September 2016 \\ Number of times this article has been viewed
}

\section{David W Polly Jr' \\ Stacey J Ackerman ${ }^{2}$ \\ Karen Schneider ${ }^{3}$ \\ Jeff B Pawelek ${ }^{4}$ \\ Behrooz A Akbarnia ${ }^{4}$}

'Department of Orthopaedic Surgery, University of Minnesota, Minneapolis,

$\mathrm{MN},{ }^{2}$ Covance Market Access Services Inc., San Diego, CA, USA; ${ }^{3}$ Covance Market Access Services Inc., Sydney, Australia; ${ }^{4}$ San Diego Spine Foundation, San Diego, CA, USA

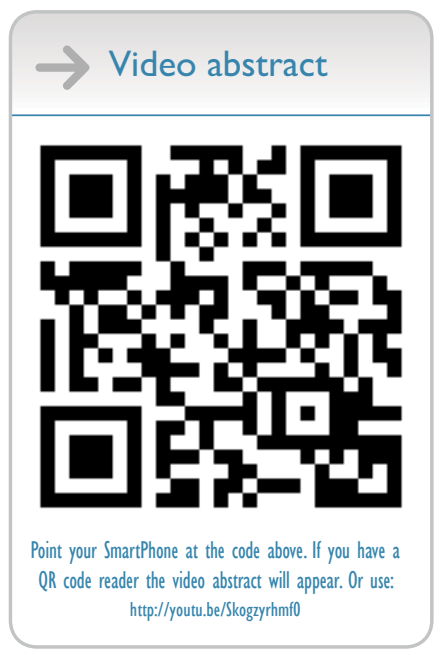

Correspondence: Stacey J Ackerman Covance Market Access Services Inc., 10300 Campus Point Drive, Suite 225, San Diego, CA 92121-151।, USA

Tel +l 8582286250

Email stacey.ackerman@covance.com
Purpose: Traditional growing rod (TGR) for early-onset scoliosis (EOS) is effective but requires repeated invasive surgical lengthenings under general anesthesia. Magnetically controlled growing rod (MCGR) is lengthened noninvasively using a hand-held magnetic external remote controller in a physician office; however, the MCGR implant is expensive, and the cumulative cost savings have not been well studied. We compared direct medical costs of MCGR and TGR for EOS from the US integrated health care delivery system perspective. We hypothesized that over time, the MCGR implant cost will be offset by eliminating repeated TGR surgical lengthenings.

Methods: For both TGR and MCGR, the economic model estimated the cumulative costs for initial implantation, lengthenings, revisions due to device failure, surgical-site infections, device exchanges (at 3.8 years), and final fusion, over a 6-year episode of care. Model parameters were estimated from published literature, a multicenter EOS database of US institutions, and interviews. Costs were discounted at 3.0\% annually and represent 2015 US dollars.

Results: Of 1,000 simulated patients over 6 years, MCGR was associated with an estimated 270 fewer deep surgical-site infections and 197 fewer revisions due to device failure compared with TGR. MCGR was projected to cost an additional \$61 per patient over the 6-year episode of care compared with TGR. Sensitivity analyses indicated that the results were sensitive to changes in the percentage of MCGR dual rod use, months between TGR lengthenings, percentage of hospital inpatient (vs outpatient) TGR lengthenings, and MCGR implant cost.

Conclusion: Cost neutrality of MCGR to TGR was achieved over the 6-year episode of care by eliminating repeated TGR surgical lengthenings. To our knowledge, this is the first cost analysis comparing MCGR to TGR - from the US provider perspective - which demonstrates the efficient provision of care with MCGR.

Keywords: early-onset scoliosis, magnetically controlled growing rods, economic model, cost analysis, traditional growing rods

\section{Introduction}

Early-onset scoliosis (EOS) is characterized by curvature of the spine $>10^{\circ}$, appearing before the age of 10 years. ${ }^{1}$ EOS can be defined as idiopathic, congenital, neuromuscular, or associated with various syndromes..$^{2-4}$ If untreated, EOS can progress to cause significant disfigurement and chest wall deformity, with the potential for worsening pulmonary insufficiency and poor quality of life. ${ }^{3}$ 
Treatment aims to monitor and assist thoracic development, focusing on controlling the structural deformity by supporting normal spinal and chest wall growth. Treatment options include casting or bracing, spinal fusion, and growthfriendly surgical techniques. ${ }^{3}$ The traditional growing rod (TGR) technique requires periodic surgical lengthenings of the device to maintain curve correction while allowing for continued spinal growth. This technique has proven useful for patients with progressive and severe curves, or for growing children for whom a delay to fusion is required to allow spine and thoracic development. ${ }^{5}$ The primary disadvantages of TGR are the risks associated with general anesthetic and wound complications due to repeated invasive surgical procedures. ${ }^{6}$ TGR surgery is also associated with substantial socioeconomic, psychological, and health-related quality-oflife (HRQoL) disadvantages for patients and their caregivers. This is due to substantial reductions in patients' normal activity levels and the indirect costs associated with the time taken from school and work for each invasive procedure. ${ }^{7}$

Recent technical advances have aimed to overcome the drawbacks associated with TGR. In particular, the magnetically controlled growing rod (MCGR) technique is a new technology in which a growing rod, once implanted during an invasive surgical procedure (similar to TGR), is lengthened noninvasively using a hand-held magnetic external remote controller. ${ }^{8}$ Using the hand-held remote controller, elongation is performed in millimeters in two ways: continuous and incremental. Continuous mode maximizes lengthening until a set force is achieved (the device's safety feature stops distraction at $\sim 42 \mathrm{lbs}$ of axial force). The incremental setting allows programmable/ custom lengthening based on patient growth chart targets. The amount of lengthening achieved is then confirmed by X-ray. The preclinical and clinical findings of treatment with MCGR have demonstrated MCGR as safe and effective over a followup period of up to 2 years. ${ }^{7-10}$ The primary advantage of the MCGR technology, compared with TGR, is that the device can be lengthened noninvasively in the physician office without anesthesia. This eliminates the need for periodic surgeries for lengthening, necessary with TGR, and has potential to reduce long-term medical resource consumption and costs in comparison to TGR and improve the HRQoL for affected children. ${ }^{11}$

The health-related costs associated with the treatment of EOS, using MCGR, have recently been shown to be lower compared with TGR in the European setting, specifically in France and the UK. Charroin et $\mathrm{al}^{11}$ reported the cumulative cost savings over 4 years to be $€ 6,135$ from the French Sickness Fund perspective. These savings were attributed to a reduction in hospital stays, periodic invasive procedures, spinal cord monitoring, anesthesia, and pharmaceutical use. In a second economic study, conducted for the UK by Rolton et al, ${ }^{12}$ the estimated cumulative cost savings per child after 5 years of treatment with MCGR compared with TGR was reported to be $£ 8,888$. One further economic study, conducted from the US payer perspective, also reported the cumulative cost savings (\$39,632 per patient at year 5) for MCGR compared with TGR. ${ }^{13}$

The objective of this research was to perform a cost analysis of MCGR compared with TGR for EOS from the US integrated health care delivery system perspective over the complete 6-year episode of care from initial implantation until final fusion. To our knowledge, this is the first cost analysis of MCGR compared to TGR performed from the provider, as opposed to the payer perspective, and the first such cost analysis that accounts for the complete episode of care. We hypothesized that over time, the higher MCGR implant cost will be offset by eliminating repeated TGR surgical lengthenings, as seen in previous research.

\section{Materials and methods Model overview}

An economic model was developed using Microsoft Excel ${ }^{\circledR}$ to compare the cost of MCGR and TGR, from the perspective of the US integrated health care delivery system. For both TGR and MCGR, the model estimated the cumulative costs associated with initial implantation, surgical revisions, device exchange, rod lengthenings, and final spinal fusion over a 6-year episode of care, from initial implantation to final fusion. The model also accounted for the occurrence of surgical-site infection (SSI; deep and superficial) and device failure.

Model parameters were estimated on the basis of published literature, analyses of a multicenter EOS database comprising the US institutions, and a series of one-on-one interviews conducted with six pediatric spine surgeons, two private payers, and two hospital purchasers. Confidential data of patients of the clinicians/hospital purchasers or of beneficiaries from payers were not obtained or used for any aspect of the cost analysis. Furthermore, interviewees themselves were not being evaluated (ie, clinician and hospital performance were not being evaluated) and, therefore, the interviewees are not considered "subjects" requiring ethics committee approval and subject consent. Rather, the interviewees provided feedback on the model framework, content (assumptions), and relevance. All costs represent 2015 US dollars, and were discounted at an annual rate of $3.0 \%$, as recommended by the Congressional Budget Office. ${ }^{14}$ The model framework and clinical parameters are reported in Table 1, and medical resource use is reported in Table 2. Of note, the TGR and MCGR device failure rates 
Table I Model framework and clinical parameters

\begin{tabular}{|c|c|c|}
\hline Parameter & Base case value (sensitivity analysis [range]) & Reference \\
\hline \multicolumn{3}{|l|}{ Model framework } \\
\hline Time horizon (years) & $6(1-6)$ & 15,16 \\
\hline \multirow[t]{2}{*}{ Size of cohort } & Per patient & NA \\
\hline & Per 1,000 patients & \\
\hline \multicolumn{3}{|l|}{ Payer mix } \\
\hline Private payer (\%) & $51.5(0-100)$ & 26,27 \\
\hline Medicaid (\%) & $48.5(0-100)$ & \\
\hline Discount rate (\% per annum) & $3.00(0.00-5.00)$ & 14 \\
\hline \multicolumn{3}{|l|}{ TGR lengthening setting of care } \\
\hline Hospital outpatient/inpatient (\%) & $45.8(0.0-100.0) / 54.2(0.0-100.0)$ & \\
\hline Hospital inpatient I-day short stay (\%) & 55.5 & 22 \\
\hline Hospital inpatient standard ward (\%) & 35.2 & \\
\hline Hospital inpatient ICU (\%) & 9.3 & Clinical practice data ${ }^{\mathrm{a}}$ \\
\hline \multicolumn{3}{|l|}{ MCGR lengthening setting of care } \\
\hline Physician office (\%) & 100.0 & b \\
\hline \multicolumn{3}{|l|}{ Device failures and SSIs } \\
\hline TGR device failure (\% per month) & $0.59(0.20-1.26)$ & \multirow{2}{*}{15,16} \\
\hline MCGR device failure (\% per month) & $0.37(0.00-0.59)$ & \\
\hline Device failures requiring complete removal (vs partial) (\%) & $5.8(2.9-11.6)$ & $18^{\mathrm{b}}$ \\
\hline SSI (\% per invasive surgery) & $2.34(1.17-4.68)$ & 18 \\
\hline Deep SSI (vs superficial) (\%) & $68(34-100)$ & $7,8,18,28-35$ \\
\hline \multicolumn{3}{|l|}{ Other risk factors } \\
\hline Device failure: single rods (vs dual rods), RR & $2.64(1.32-5.28)$ & 18 \\
\hline SSI: Medicaid patients (vs all other patients), RR & $2.06(1.19-3.58)$ & 36 \\
\hline
\end{tabular}

Notes: a ${ }^{E}$ stimate based on experience at one facility where three of $4 \mathrm{I}$ patients (conservatively, $\sim 5 \%$ ) had an ICU stay, whereby half were undergoing the lengthening on an inpatient basis and the other half on an outpatient basis. ${ }^{b}$ Clinical advisors.

Abbreviations: ICU, intensive care unit; MCGR, magnetically controlled growing rod; NA, not applicable; RR, relative risk; SSI, surgical site infection; TGR, traditional growing rod.

Table 2 Resource use

\begin{tabular}{|c|c|c|}
\hline Parameter & $\begin{array}{l}\text { Base case value } \\
\text { (sensitivity } \\
\text { analysis [range]) }\end{array}$ & Reference \\
\hline Months between MCGR lengthenings & $3.0(1.0-6.0)$ & 15,16 \\
\hline Months between TGR lengthenings & $6.0(6.0-12.0)$ & 37 \\
\hline Percentage of dual rods (\%) & $85.0(0.0-100.0)$ & $22^{\mathrm{a}}$ \\
\hline Years to implant exchange & $3.8(3.0-5.0)$ & $17^{\mathrm{a}}$ \\
\hline $\begin{array}{l}\text { Wedding band use for TGR single- } \\
\text { rod constructs (\%) }\end{array}$ & 15.00 & $22^{\mathrm{a}}$ \\
\hline $\begin{array}{l}\text { Tandem connector use for TGR } \\
\text { single-rod constructs (\%) }\end{array}$ & 47.00 & \\
\hline $\begin{array}{l}\text { Wedding band use for TGR dual-rod } \\
\text { constructs (\%) }\end{array}$ & 28.00 & \\
\hline $\begin{array}{l}\text { Tandem connector use for TGR } \\
\text { dual-rod constructs }(\%)\end{array}$ & 67.00 & \\
\hline $\begin{array}{l}\text { Cross link use for TGR dual-rod } \\
\text { constructs (\%) }\end{array}$ & 86.00 & \\
\hline $\begin{array}{l}\text { Cross link use for MCGR dual-rod } \\
\text { constructs (\%) }\end{array}$ & 86.00 & $22^{\mathrm{a}}$ \\
\hline
\end{tabular}

Note: a Clinical advisors.

Abbreviations: MCGR, magnetically controlled growing rod; TGR, traditional growing rod.

were obtained from a previously conducted economic evaluation commissioned by the National Institute for Health and Care Excellence, as reported in the external assessment center report ${ }^{15}$ and journal publication. ${ }^{16}$ These rates were calculated based on the best available evidence.

\section{Model assumptions and data sources}

Assumptions made in the development of this model include the following: clinical effectiveness (curve correction and increase in thoracic height) is equivalent between MCGR and TGR; ${ }^{10}$ resource use between TGR and MCGR with respect to initial implantation, revision, exchange, and final fusion is similar (with the exception of the device cost, where appropriate); one $\mathrm{X}$-ray is required per insertion, lengthening procedure, exchange, revision, deep SSI, and final fusion; all patients for MCGR and TGR require one device exchange surgery at 3.8 years, based on the average spine growth observed in a child aged 6 years; ${ }^{17}$ and deep SSI requires a complete replacement of implants, and superficial infection requires oral antibiotics.

The components replaced during a partial revision procedure (Table 2) were based on the study of Bess et $\mathrm{al}^{18}$ and expert clinical advice. Among patients with partial removal, pedicle screw/hooks were assumed to be replaced $95 \%$ of the time, rod set screws $61 \%$ of the time, and all other components (including rods and connectors) 100\% of the time. It was further assumed that MCGR costs were not incurred for partial or complete revisions due to MCGR failure within 1 year following an MCGR implantation or MCGR exchange (in the unlikely event of a manufacturing defect); other costs for the revisions were incurred (eg, hospital facility costs and professional fees). For revisions 
Table 3 Total costs used in the model (2015 USD)

\begin{tabular}{|c|c|c|}
\hline Parameter & Base case value (sensitivity analysis [range]) & Reference \\
\hline TGR rod cost & $\$ 750(\$ 563-I, I 25)$ & NuVasive Specialized \\
\hline MCGR rod cost & $\$ 17,500(\$ 13,125-21,875)$ & Orthopedics \\
\hline TGR insertion ${ }^{\mathrm{a}}$ & $\$ 34,555$ & Medicare payment as a proxy for \\
\hline MCGR insertion ${ }^{\mathrm{a}}$ & $\$ 64,579$ & $\operatorname{costs}^{24}$ (eg, CPT, DRG, APC) \\
\hline TGR lengthening (weighted) & $\$ 6,327$ & \\
\hline Outpatient (weight $=45.8 \%$ ) & $\$ 4,378$ & \\
\hline Inpatient I-day short stay (weight $=0.542 \times 0.555=30 \%)$ & $\$ 4,378$ & \\
\hline Inpatient standard ward (weight $=0.542 \times 0.352=19 \%)$ & $\$ 12,003$ & \\
\hline Inpatient ICU (weight $=0.542 \times 0.093=5 \%)$ & $\$ 14,177$ & \\
\hline MCGR lengthening (physician office) & $\$ 176$ & \\
\hline TGR exchange ${ }^{\mathrm{a}}$ & $\$ 12,672$ & \\
\hline MCGR exchange ${ }^{a}$ & $\$ 42,696$ & \\
\hline TGR complete revision ${ }^{\mathrm{a}}$ & $\$ 12,672$ & \\
\hline MCGR complete revision ${ }^{\mathrm{a}}$ & $\$ 42,696$ & \\
\hline TGR partial revision ${ }^{\mathrm{a}}$ & $\$ 11,475$ & \\
\hline MCGR partial revision ${ }^{\mathrm{a}}$ & $\$ 41,500$ & \\
\hline TGR deep SSI & $\$ 12,672$ & \\
\hline MCGR deep SSI ${ }^{\mathrm{a}}$ & $\$ 43,557$ & \\
\hline TGR removal and final fusion & $\$ 35,967$ & \\
\hline MCGR removal and final fusion & $\$ 35,967$ & \\
\hline
\end{tabular}

Notes: The total costs in this table were used in conjunction with clinical parameters and medical resource use percentages to derive cumulative costs. ${ }^{\text {a Growing rod device }}$ costs included.

Abbreviations: APC, ambulatory payment classification; CPT, current procedural terminology; DRG, diagnosis-related group; ICU, intensive care unit; MCGR, magnetically controlled growing rod; SSI, surgical site infection; TGR, traditional growing rod; USD, US dollars.

due to anchor or foundation issues within 1 year following an MCGR implantation or MCGR exchange, it was assumed that the MCGRs did not require replacement.

Hospital inpatient facility costs were based on Medicare payments (diagnosis-related group [DRG] data), physician professional fees were based on current procedural terminology data, and hospital outpatient facility costs were based on ambulatory payment classification data. Because bundled DRG payments include the TGR device cost, for MCGR hospital inpatient procedures, the TGR device costs were subtracted from the DRG payment, and the MCGR device costs were added to account for the difference in device cost. The total costs for procedures included in the model are shown in Table 3. Unit costs for these procedures, including all DRG, current procedural terminology, and ambulatory payment classification codes and costs, as well as X-ray, intraoperative neurophysiological monitoring, and anesthesia codes and costs, can be viewed in the Supplementary materials.

\section{Sensitivity analysis}

Extensive one-way sensitivity analyses were conducted on a range of model variables to establish how robust the cumulative cost savings were to realistic changes in the boundaries of the key parameters and assumptions of the model. The lower and upper bounds for these parameters are outlined in Tables 1-3 and the Supplementary materials. Two-way sensitivity analyses were also conducted for device failure rate and the months between lengthenings.

\section{Results \\ Base-case results}

Over the 6-year episode of care, MCGR was associated with an estimated 11.2 fewer invasive procedures per patient compared with TGR (MCGR: 3.33; TGR: 14.53). When simulating 1,000 EOS patients over the 6-year episode of care, MCGR was associated with an estimated 270 fewer deep SSIs (MCGR: 80; TGR: 350) and 197 fewer revisions due to device failure compared with TGR (MCGR: 332; TGR: 529).

The cumulative costs for treatment of EOS with MCGR compared with TGR are illustrated in Figure 1. As shown in Figure 1, the higher cost associated with the initial insertion and exchange (at 3.8 years) of MCGR was offset by the repeated TGR surgical lengthenings and associated complications. The cumulative cost for MCGR vs TGR over the 6-year episode of care was cost neutral (\$61; MCGR minus TGR) from the US integrated health care delivery system perspective.

\section{Sensitivity analysis}

Extensive sensitivity analyses were conducted. As shown in the one-way sensitivity analysis (Figure 2), the cumulative cost savings of MCGR was most sensitive to MCGR dual rod use, months between TGR lengthenings, TGR lengthenings 


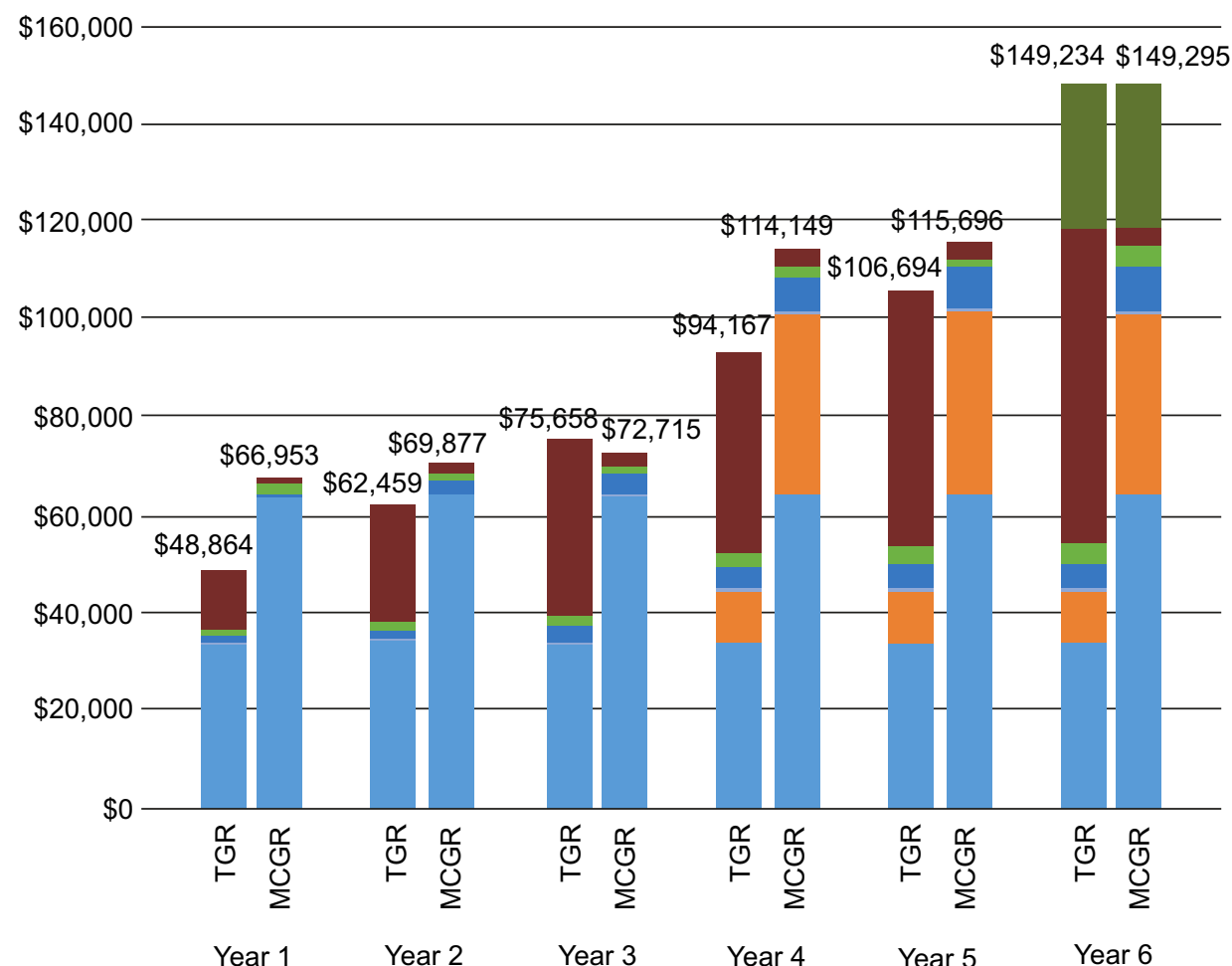

Insertion

Exchange

Revision with complete removal

Revision with partial removal

Deep infection

Distraction

Removal and final fusion

Figure I Cumulative cost, per patient (2015 USD).

Notes: This figure illustrates the cumulative costs per patient for treatment of early-onset scoliosis with MCGR compared with TGR over the 6-year episode of care. Exchange surgery conducted at 3.8 years. The cumulative costs presented in this figure are calculated based on total costs, clinical parameters, and medical resource use percentages.

Abbreviations: MCGR, magnetically controlled growing rod; TGR, traditional growing rod; USD, US dollars.

$\square$ Lower parameter estimate

$\square$ Higher parameter estimate $\quad \%$ of MCGR dual rods Months between TGR lengthenings $\%$ inpatient (vs outpatient) TGR distraction MCGR rod cost Time horizon (years) MCGR device failure (per month)

TGR device failure (per month) Months between MCGR lengthenings

TGR SSI (per invasive surgery) MCGR SSI (per invasive surgery) Relative risk of device failure with single MCGR rods TGR $\%$ of SSIs that are deep infections Discount rate MCGR \% of SSls that are deep infections Relative risk of device failure with single TGR rods $\%$ of TGR dual rods TGR rod cost Years to MCGR exchange Anesthesia cost Relative risk of SSI associated with Medicaid patients $\%$ Medicaid (vs private payer) Years to TGR exchange TGR \% of device failures that require complete removal MCGR \% of device failures that require complete removal

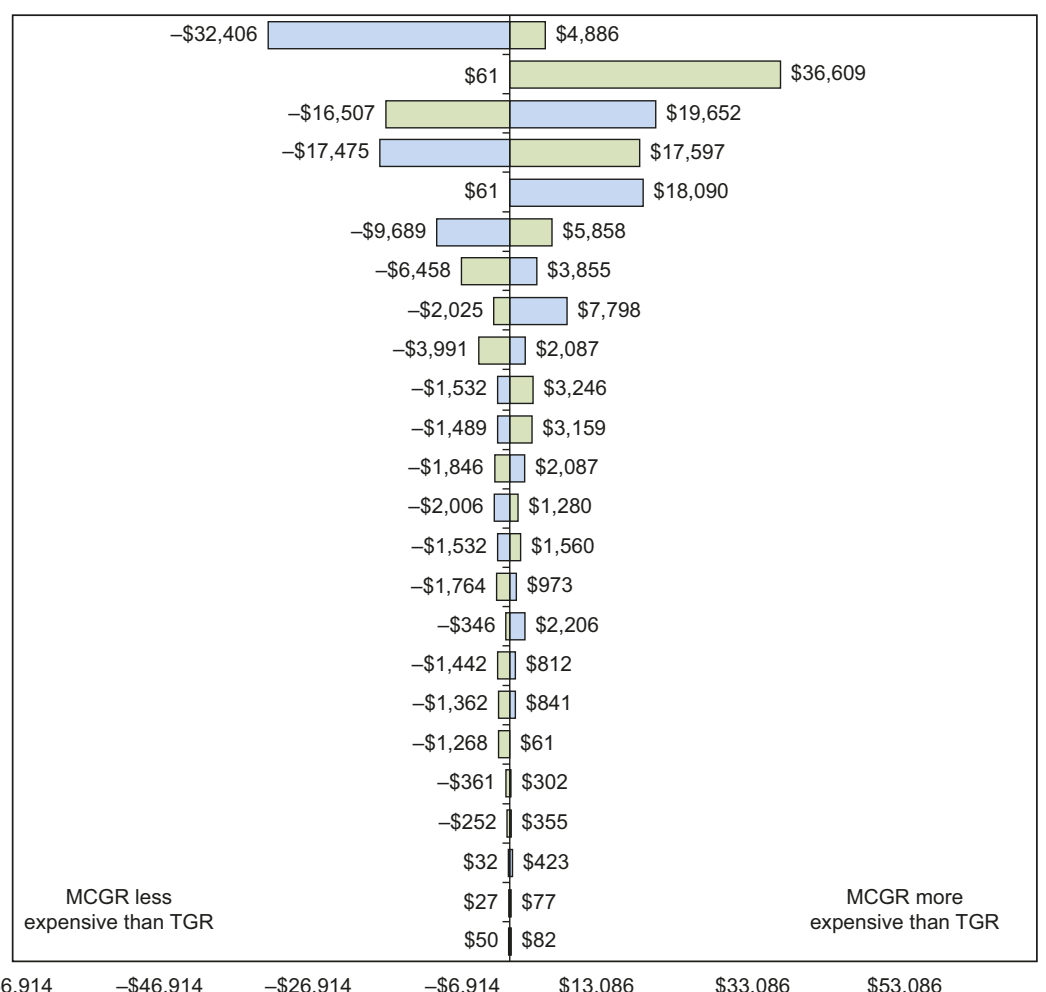

$-\$ 66,914 \quad-\$ 46,914 \quad-\$ 26,914$

$-\$ 6,914 \quad \$ 13,086$

$\$ 53,086$

Figure 2 One-way sensitivity analysis of cumulative cost savings per patient (2015 USD).

Notes: This figure illustrates how sensitive the primary outcome is to changes in the model parameters. Lowering the parameter is represented in blue, and increasing the parameter is represented in green.

Abbreviations: MCGR, magnetically controlled growing rod; SSI, surgical site infection; TGR, traditional growing rod; USD, US dollars. 
that are inpatient (vs outpatient), MCGR cost, and time horizon. The results were less sensitive to the percent of SSIs that are deep infections and years to exchange surgery. When less certain model parameters were varied in the two-way sensitivity analyses, specifically the MCGR device failure rate (Figure 3) and months between MCGR lengthenings (Figure 4), the costs fell within a relatively narrow range when based on realistic clinical scenarios, suggesting that the economic model is robust to plausible parameter values.

In the base-case analysis that evaluated cumulative 6-year costs, the differential was $\$ 61$; that is, cost neutrality was achieved by the conclusion of the 6-year episode of care. The results were sensitive, however, to the time horizon due to the timing of certain procedures in the process of care, most notably the exchange surgery at 3.8 years. As a result, $\sim 73 \%$ of the cumulative costs for MCGR were accrued in year 1 (initial implantation) and year 4 (exchange surgery); these costs were then offset over time.

\section{Discussion}

Economic models facilitate exploring the extent to which costs of a new intervention may be offset by reductions in other medical costs. ${ }^{19}$ The economic model presented in this study demonstrates that the cost impact of MCGR is offset by eliminating repeated TGR surgical lengthenings and associated complications. The cost offsets for MCGR were driven by fewer deep SSIs, less device failures resulting in fewer revisions, and absence of a hospital inpatient stay,

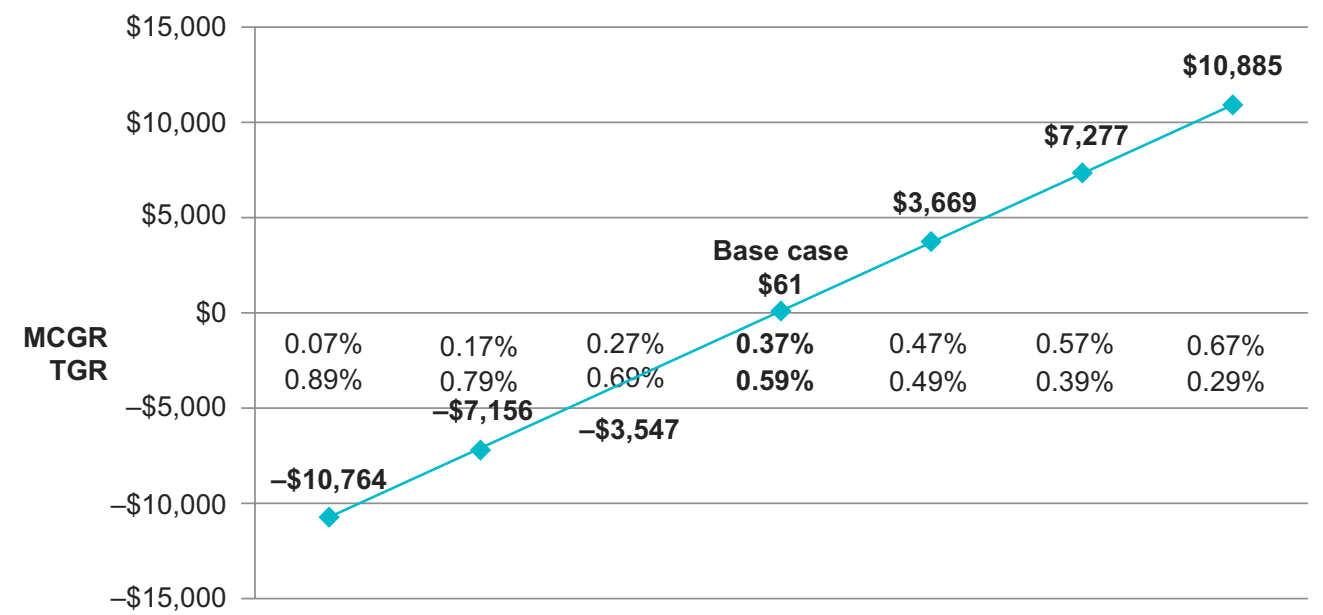

Figure 3 Two-way sensitivity analysis of device failure (cumulative cost savings per patient, 20I5 USD).

Notes: This figure illustrates how sensitive the primary outcome is to variation in device failure. A negative result indicates cost savings for MCGR, and a positive result indicates increased costs for MCGR.

Abbreviations: MCGR, magnetically controlled growing rod; TGR, traditional growing rod; USD, US dollars.

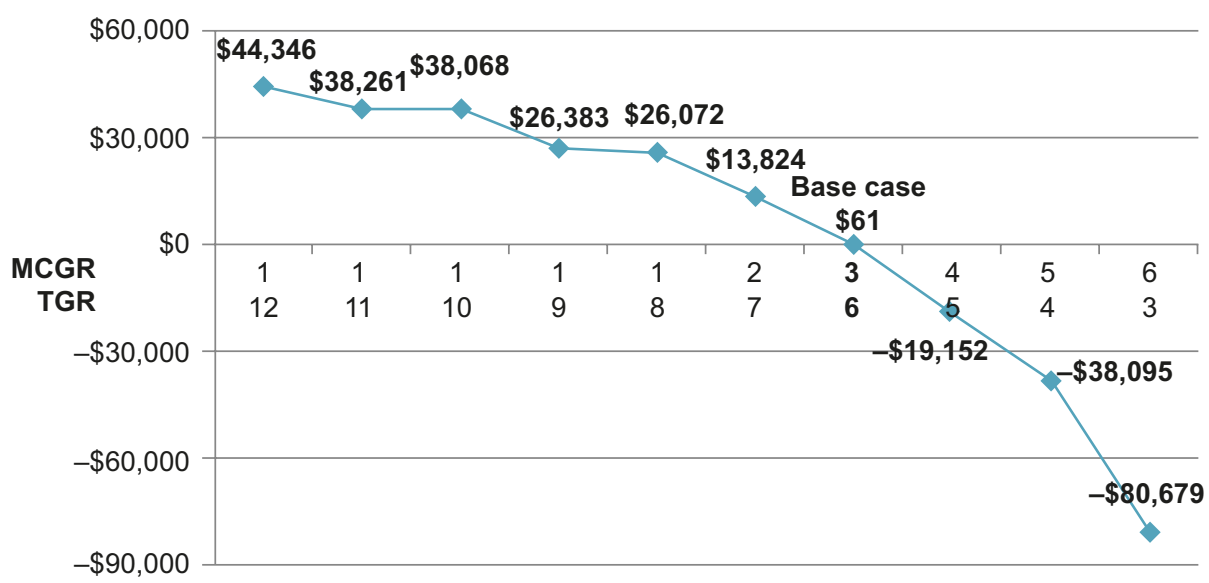

Figure 4 Two-way sensitivity analysis of months between lengthenings (cumulative cost savings per patient, 2015 USD).

Notes: This figure illustrates how sensitive the primary outcome is to variation in months between lengthenings. A negative result indicates cost savings for MCGR, and a positive result indicates increased costs for MCGR.

Abbreviations: MCGR, magnetically controlled growing rod; TGR, traditional growing rod; USD, US dollars. 
anesthesia, and intraoperative neurophysiological monitoring during MCGR lengthenings. In the US, providers are becoming increasingly at financial risk as bundled payments shift the risk of financial accountability from the payer to the provider. ${ }^{20}$ With the trend toward bundled payments in orthopedics, providers will be at risk for a defined episode of care, including hospital stays, complications, and implant costs. ${ }^{21}$ This cost analysis demonstrates, from a provider perspective, the efficient provision of care with MCGR.

Our analysis differs in several ways from previous analyses of MCGR conducted for the European and the US settings of care. ${ }^{11-13}$ Most notably, our analysis evaluated cumulative costs over the 6-year episode of care (from initial implantation through final fusion) - inclusive of the exchange surgery at 3.8 years for both TGR and MCGR. In addition, our analysis reflected the US practice patterns where the majority $(85 \%)$ of cases use dual-rod rather than single-rod constructs, and TGR lengthenings are performed in both the hospital inpatient and outpatient settings (with more frail children requiring greater resources such as an intensive care unit stay). ${ }^{22}$ On the other hand, the UK study by Rolton et al, ${ }^{12}$ the French study by Charroin et al, ${ }^{11}$ and the US payer perspective study by Su et $\mathrm{al}^{13}$ all demonstrated cumulative cost savings without accounting for the exchange surgery and assumed that TGR lengthenings are performed entirely in the hospital inpatient setting. These differences in modeling approaches may represent variations in either practice patterns or modeling assumptions.

Charroin et $\mathrm{al}^{11}$ and $\mathrm{Su}$ et $\mathrm{a}^{13}$ explain that their time horizons (4 and 5 years, respectively) were selected to accommodate the complete lengthening capacity of MCGR $(4.8 \mathrm{~cm})$, not necessarily a full episode of care. After achieving MCGR maximal range of lengthening at $4.8 \mathrm{~cm}$, Su et al ${ }^{13}$ acknowledged that MCGR is likely to require an exchange to accommodate further growth. In the present study at 3 years following initial implantation and prior to the exchange surgery at 3.8 years, MCGR resulted in a cumulative cost savings of $\$ 2,943$ compared to TGR (Figure 1), which is consistent with the prior research studies that did not account for the exchange surgery. This finding of cumulative cost savings at 3 years following initial implantation of MCGR may also apply to surgeries involving conversions of TGR to MCGR where an MCGR exchange procedure is not anticipated. ${ }^{23}$

As noted previously, we performed a cost analysis of MCGR compared with TGR for EOS from the US provider perspective, whereas $\mathrm{Su}$ et $\mathrm{al}^{13}$ performed a similar analysis but from the US payer perspective. We used Medicare payments as a proxy for provider costs, a well-accepted methodology in economic analyses. ${ }^{24}$ On the other hand, Su et al ${ }^{13}$ determined costs using the Kids' Inpatient Database in the NIS Healthcare Cost and Utilization Project Database. Of note, the database contains hospital charge data (as reflected on a hospital bill), not insurer payments or the actual cost to the hospital for the provision of care to the patient. Given that insurers generally pay less than hospital charges, ${ }^{25}$ it remains unclear to what degree the use of hospital charges may have affected the difference in cumulative costs between TGR and MCGR reported by $\mathrm{Su}$ et al. ${ }^{13}$

Further, in our study, we incorporated a distribution of practice settings (roughly half hospital inpatient and half hospital outpatient) for performing TGR lengthenings based on a multicenter EOS database comprising US institutions, ${ }^{22}$ whereas $\mathrm{Su}$ et $\mathrm{al}^{13}$ assumed that TGR lengthenings were performed entirely in the hospital inpatient setting in the US. The approximate Medicare reimbursement for TGR lengthenings is $\$ 6,000$ (when considering both practice settings), compared to the $\$ 10,000$ in hospital inpatient charges noted by $\mathrm{Su}$ et al. ${ }^{13}$ If one takes $60 \%$ of the cumulative cost of TGR lengthenings estimated by $\mathrm{Su}$ et al, ${ }^{13}$ the cost savings of MCGR reported by Su et $\mathrm{al}^{13}$ are diminished; nevertheless, it appears that MCGR would be cost neutral in year 5 from the US payer perspective, which is similar to our results at year 6 from the US provider perspective.

Overall, the study by Su et $\mathrm{al}^{13}$ seems to be a "best case" analysis of the potential cost savings associated with MCGR for the treatment of EOS. The UK study by Rolton et $\mathrm{al}^{12}$ and the French study by Charroin et $\mathrm{al}^{11}$ are perhaps slightly less so but still show cost savings. Our cost analysis by comparison is more conservative. Nonetheless, the trend in all of these studies is that while there is an added expense from the new technology, the cost offsets appear to economically justify the adoption of MCGR. With use of MCGR, there is substantial value from obviating repeat anesthetic and surgical events, as well as avoiding family disruption. The significant yet unquantified clinical benefit - and associated financial benefit - from avoiding repeated surgical TGR lengthenings warrants further investigation.

\section{Limitations}

At present, the MCGR literature on device failure is limited to small numbers of patients with a follow-up period of 2 years. Sensitivity analyses were performed on the MCGR device failure rate in light of this limitation. Where data for MCGR were not available from the published literature, conservative assumptions were made by using the same parameter values as for TGR based on TGR clinical studies, in particular the study by Bess et al. ${ }^{18}$ When these less certain MCGR clinical parameters were varied within a plausible range, the 
inferences of the model did not change suggesting that the model is robust.

While not a limitation per se, it is worth noting that the model presented is a cost analysis and not a cost-effectiveness analysis. Therefore, similar to previous economic research of MCGR, it has not accounted for, 1) the pain, psychological distress, and compromised HRQoL associated with invasive TGR lengthening surgeries, or 2) the shorter recovery time with MCGR lengthenings, which results in less time away from usual activities for young patients and their families. Therefore, further analyses developed specifically to measure and evaluate HRQoL should be considered for future research.

\section{Conclusion}

Cost offsets for MCGR accrue over time and reflect the elimination of repeated invasive TGR surgical lengthenings and their associated complications. Despite the higher up-front cost for insertion of the MCGR implant and later for exchange of the MCGR implant, the cumulative cost of MCGR is offset over the 6-year episode of care from the perspective of the US integrated health care delivery system. The HRQoL gained by MCGR patients and their caregivers is likely to be substantial and warrants further investigation.

\section{Disclosure}

This study was sponsored, in part, by NuVasive Specialized Orthopedics. SJA and KS are consultants to NuVasive through their employment at Covance. (As salaried employees of Covance, no direct compensation was received by these authors; payments were made directly to Covance.) BAA receives grant support to his institution from NuVasive. In addition, BAA is a consultant to K2M and NuVasive, holds stock in NuVasive and NociMed, and receives royalties from Depuy Synthes, K2M, and NuVasive. DWP and JBP report no conflicts of interest in this work. The sponsor, NuVasive Specialized Orthopedics, did not participate in the data analysis, interpretation of the results, or the writing of this manuscript.

\section{References}

1. El-Hawary R, Akbarnia BA. Early onset scoliosis - time for consensus. Spine Deform. 2015;3(2):105-106.

2. Cunin V. Early-onset scoliosis: current treatment. Orthop Traumatol Surg Res. 2015;101(1 Suppl):S109-S118.

3. Fletcher ND, Bruce RW. Early onset scoliosis: current concepts and controversies. Curr Rev Musculoskelet Med. 2012;5(2):102-110.

4. Williams BA, Matsumoto H, McCalla DJ, et al. Development and initial validation of the Classification of Early-Onset Scoliosis (C-EOS). J Bone Joint Surg Am. 2014;96(16):1359-1367.

5. Moe JH, Kharrat K, Winter RB, Cummine JL. Harrington instrumentation without fusion plus external orthotic support for the treatment of difficult curvature problems in young children. Clin Orthop Relat Res. 1984;(185):35-45.
6. Backeljauw B, Holland SK, Altaye M, Loepke AW. Cognition and brain structure following early childhood surgery with anesthesia. Pediatrics. 2015;136(1):e1-e12.

7. Cheung KM, Cheung JP, Samartzis D, et al. Magnetically controlled growing rods for severe spinal curvature in young children: a prospective case series. Lancet. 2012;379(9830):1967-1974.

8. Akbarnia BA, Cheung K, Noordeen H, et al. Next generation of growthsparing techniques: preliminary clinical results of a magnetically controlled growing rod in 14 patients with early-onset scoliosis. Spine (Phila Pa 1976). 2013;38(8):665-670.

9. Akbarnia BA, Mundis GM Jr, Salari P, Yaszay B, Pawelek JB. Innovation in growing rod technique: a study of safety and efficacy of a magnetically controlled growing rod in a porcine model. Spine (Phila Pa 1976). 2012;37(13):1109-1114.

10. Akbarnia BA, Pawelek JB, Cheung KM, et al. Traditional growing rods versus magnetically controlled growing rods for the surgical treatment of early-onset scoliosis: a case-matched 2-year study. Spine Deform. 2014;2(6):493-497.

11. Charroin C, Abelin-Genevois K, Cunin V, et al. Direct costs associated with the management of progressive early onset scoliosis: estimations based on gold standard technique or with magnetically controlled growing rods. Orthop Traumatol Surg Res. 2014;100(5):469-474.

12. Rolton D, Richards J, Nnadi C. Magnetic controlled growth rods versus conventional growing rod systems in the treatment of early onset scoliosis: a cost comparison. Eur Spine J. 2015;24(7):1457-1461.

13. Su AW, Milbrandt TA, Larson AN. Magnetic expansion control system achieves cost savings compared to traditional growth rods: an economic analysis model. Spine (Phila Pa 1976). 2015;40(23):1851-1856.

14. CBO.gov [report on the Internet]. CBO's 2011 long-term projections for social security: additional information [cited August 5, 2011]. Available from: https://www.cbo.gov/publication/41644. Accessed September 30, 2014.

15. Craig J, Jenks M, Willits I, et al. NICE external assessment centre report: MAGEC system for spinal lengthening in children with early onset scoliosis [cited November 2013]. Available from: https://www. nice.org.uk/guidance/mtg18/chapter/8-sources-of-evidence-consideredby-the-committee. Accessed April 1, 2015.

16. Jenks M, Craig J, Higgins J, et al. The MAGEC system for spinal lengthening in children with scoliosis: a NICE medical technology guidance. Appl Health Econ Health Policy. 2014;12(6):587-599.

17. Moe JH, Winter RB, Bradford DS, Lonstein JE. The normal spine: anatomy, embryology, and growth. In: Moe JH, Winter RB, Bradford DS, Lonstein JE, editors. Scoliosis and Other Spinal Deformities. Philadelphia, PA: WB Saunders Co; 1978:78-79.

18. Bess S, Akbarnia BA, Thompson GH, et al. Complications of growingrod treatment for early-onset scoliosis: analysis of one hundred and forty patients. J Bone Joint Surg Am. 2010;92(15):2533-2543.

19. Buchowski JM, Kebaish KM, Sinkov V, Cohen DB, Sieber AN, Kostuik JP. Functional and radiographic outcome of sacroiliac arthrodesis for the disorders of the sacroiliac joint. Spine J. Sep-Oct 2005;5(5):520-528; discussion 529.

20. CMS.gov [homepage on the Internet]. Baltimore: Centers for Medicare and Medicaid Services [updated 2016 Jul 19]. Available from: http://innovation. cms.gov/initiatives/bundled-payments/. Accessed August 31, 2015.

21. Federalregister.gov [homepage on the Internet]. Baltimore: Centers for Medicare \& Medicaid Services [cited 2015 Jul 14]. Available from: http://federalregister.gov/a/2015-17190. Accessed August 31, 2015.

22. Growing Spine Study Group Research Database [database not available on the Internet]. Milwaukee, WI: Growing Spine Foundation; 2015. Accessed May 20, 2015.

23. Heli K, Ilkka H, Colin N, et al. Comparison of primary and conversion surgery with magnetically controlled growing rods in children with early onset scoliosis. Paper presented at: Annual Meeting of the Nordic Spinal Deformities Society; August 27-29, 2015; Amsterdam, The Netherlands.

24. Weinstein MC, Siegel JE, Gold MR, Kamlet MS, Russell LB. Recommendations of the panel on cost-effectiveness in health and medicine. JAMA. 1996;276(15):1253-1258. 
25. Brown K, Webster M. Hospital charges are not related to actual costs or other commonly suggested factors. Colorado Center on Law \& Policy website. Issue Brief. [cited 2013 Aug 15]. Available from: http://cclponline.org/ wp-content/uploads/2013/10/Our-Dollars-Our-Health-Part-2_Hospitalcharges-are-not-related-to-actual-costs-or-other-commonly-suggestedfactors_DOC-8.15.13.pdf. Accessed September 15, 2015.

26. CDC.gov [database on the Internet]. Centers for Disease Control and Prevention. National Hospital Discharge Survey - Database enquiry 2006-2015. [updated 2015 Sep 2]. Available from: http://www.cdc. gov/nchs/nhds.htm. Accessed April 1, 2015.

27. CDC.gov [database on the Internet]. Centers for Disease Control and Prevention. National Hospital Ambulatory Medical Care Survey Database enquiry 2006-2015. [updated 2015 Sep 23]. Available from: http://www.cdc.gov/nchs/ahcd.htm. Accessed April 1, 2015.

28. Dannawi Z, Altaf F, Harshavardhana NS, El Sebaie H, Noordeen H. Early results of a remotely-operated magnetic growth rod in early-onset scoliosis. Bone Joint J. 2013;95-B(1):75-80.

29. Hickey BA, Towriss C, Baxter G, et al. Early experience of MAGEC magnetic growing rods in the treatment of early onset scoliosis. Eur Spine J. 2014;23(Suppl 1):S61-S65.

30. Thompson GH, Akbarnia BA, Kostial P, et al. Comparison of single and dual growing rod techniques followed through definitive surgery: a preliminary study. Spine (Phila Pa 1976). 2005;30(18):2039-2044.
31. Farooq N, Garrido E, Altaf F, et al. Minimizing complications with single submuscular growing rods: a review of technique and results on 88 patients with minimum two-year follow-up. Spine (Phila Pa 1976). 2010; 35(25):2252-2258.

32. Andras LM, Joiner ERA, McCarthy RE, et al. Growing rods versus shilla growth guidance: better cobb angle correction and T1-S1 length increase but more surgeries. Spine Deform. 2015;3(3):246-252.

33. McElroy MJ, Shaner AC, Crawford TO, et al. Growing rods for scoliosis in spinal muscular atrophy: structural effects, complications, and hospital stays. Spine (Phila Pa 1976). 2011;36(16):1305-1311.

34. McElroy MJ, Sponseller PD, Dattilo JR, et al. Growing rods for the treatment of scoliosis in children with cerebral palsy: a critical assessment. Spine (Phila Pa 1976). 2012;37(24):E1504-E1510.

35. Schroerlucke SR, Akbarnia BA, Pawelek JB, et al. How does thoracic kyphosis affect patient outcomes in growing rod surgery? Spine (Phila Pa 1976). 2012;37(15):1303-1309.

36. Manoso MW, Cizik AM, Bransford RJ, Bellabarba C, Chapman J, Lee MJ. Medicaid status is associated with higher surgical site infection rates after spine surgery. Spine (Phila Pa 1976). 2014;39(20):1707-1713.

37. Akbarnia BA, Marks DS, Boachie-Adjei O, Thompson AG, Asher MA Dual growing rod technique for the treatment of progressive early-onset scoliosis: a multicenter study. Spine (Phila Pa 1976). 2005;30(17 Suppl) S46-S57.

\section{ClinicoEconomics and Outcomes Research}

\section{Publish your work in this journal}

ClinicoEconomics and Outcomes Research is an international, peerreviewed open-access journal focusing on health technology assessment, pharmacoeconomics and outcomes research in the areas of diagnosis, medical devices, and clinical, surgical and pharmacological intervention. The economic impact of health policy and health systems
Submit your manuscript here: https://www.dovepress.com/clinicoeconomics-and-outcon-es-rearch-jor

organization also constitute important areas of coverage. The manuscript management system is completely online and includes a very quick and fair peer-review system, which is all easy to use. Visit http://www.dovepress.com/testimonials.php to read real quotes from published authors. 